\title{
Ionic Transport in Poly(ethylene oxide) (PEO)-LiX Polymeric Solid Electrolyte
}

\author{
M. Z. A. MUNSHI and B. B. OWENS \\ Corrosion Research Center, University of Minnesota, \\ 112 Amundson Hall, 221 Church Street, SE, \\ Minneapolis, MN 55455, U.S.A.
}

(Received January 5, 1988)

\begin{abstract}
The ionic conductivity behavior of poly(ethylene oxide) complexed with lithium salts was investigated using an a.c. impedance technique. The composition range of the salt was from 0.01 to 0.5 mole fraction. The result showed that anions strongly influence the conductivity behavior of the polymer electrolyte. A simple model is proposed whereby the conductivity decrease at higher salt concentration is due to ion-pair formation. This results in an increase in the activation energy with increasing salt concentration and a reduction in the ionic mobility of $\mathrm{Li}^{+}$ions.

KEY WORDS Polymer Electrolytes / Poly(ethylene oxide) / Conductivity / Ionic Transport / Ion-Pair /
\end{abstract}

Fast ion transport was first demonstrated by Fenton et al., ${ }^{1}$ on polymer solid electrolytes based on poly(ethylene oxide) (PEO) and an alkali metal salt at about $100^{\circ} \mathrm{C}$. This was followed by Armand's proposal ${ }^{2}$ for an allsolid state lithium battery. Since then there has been considerable interest in developing electrolytes based on these and other types of polymeric materials ${ }^{3-20}$ for use in high energy denisty batteries. PEO is by far the most widely studied polymer electrolyte. The pure polymer is highly crystalline $(>60 \%)$ with a glass transition temperature of $213^{\circ} \mathrm{K}$. The complex formed between PEO and an alkali metal salt imparts a high ionic conductivity in the elastomeric phase at tempertures above the melting point of PEO. However, the mechanism of ionic transport is not well understood. This is mainly due to a difference in opinion concerning the structure of the complex. The general occurrence of the complex at a stoichiometry of 4:1 PEO: Li salt (termed O:Li ratio) led to the proposal of a helical strucute of the PEO strands with the lithium ions placed at the core of the helix ${ }^{2}$.

However, this has recently been shown ${ }^{21}$ to be in disagreement with experimental findings. The stoichiometry of the complex has been found to vary and $\mathrm{O}: \mathrm{Li}$ ratios as low as $2.5: 1$ have been found to exist. ${ }^{22} \mathrm{X}$-ray analyses have shown the $\mathrm{Li}^{+}$ions occupy positions outside the helical PEO strands. This would explain the observed stoichiometries lower than $4: 1, \mathrm{O}: \mathrm{Li}$. This conformation would result in a minimum coulombic repulsion ${ }^{23}$ from the oxygen lone pairs.

Phase diagrams of the PEO-LiX systems have shown that the complex formed is not single-phase but exists in two or more phases. At room temperature, three phases coexist; the pure PEO crystals, the salt rich stoichiometric crystalline complex and the amorphous phase. As the temperature is raised above $65^{\circ} \mathrm{C}$, the crystalline PEO melts in the amorphous phase. It is at these elevated temperatures that the conductivity of the electrolyte becomes significant.

Numerous studies have been made to eluci- 
date the conductivity of the polymer material containing different salts. The most commonly studied salt has been $\mathrm{LiCF}_{3} \mathrm{SO}_{3}$. Other salts have been investigated but the relationship between the conductivity and the ionic size of the salts have not been well documented. Previous results ${ }^{10}$ on polypropylene oxide based electrolytes have shown that the ionic conductivity of the polymer increases with increasing ionic size of salt. It is envisaged that PEO would behave in a similar manner. This paper reports on the effect of the ionic size of lithium salts in PEO on conductivity. The conductivity parameter is important since it influences the polarization characteristics in electrochemical cells. The present study was made on five salts with six different PEO-LiX compositions.

\section{EXPERIMENTAL}

\section{Preparation of Polymer-LiX Mixtures}

Poly(ethylene oxide) of molecular weight $5 \times 10^{6}$ was supplied by Polysciences in powdered form. The material was dried at $50^{\circ} \mathrm{C}$ for several days prior to its use. The lithium salts were dried at the temperatures specified below; $\mathrm{LiCF}_{3} \mathrm{SO}_{3}(3 \mathrm{M})$ at $50^{\circ} \mathrm{C}$ for several days, $\mathrm{LiAsF}_{6}$ (Alfa) used as received, $\mathrm{LiBF}_{4}$ (Alfa) $50^{\circ} \mathrm{C}$ for $24 \mathrm{~h}, \mathrm{LiAlCl}_{4}$ (Lithcoa) used as received and $\mathrm{LiPF}_{6}$ (Ozark) $50^{\circ} \mathrm{C}$ for $24 \mathrm{~h}$. All subsequent handling of the materials was carried out in a $<1 \%$ relative humidity dry room. All of these lithium salts and the PEO dissolve fairly easily in acetonitrile and films were cast from this solvent.

To form the films, known weights of the appropriate salts were dissolved in acetonitrile.

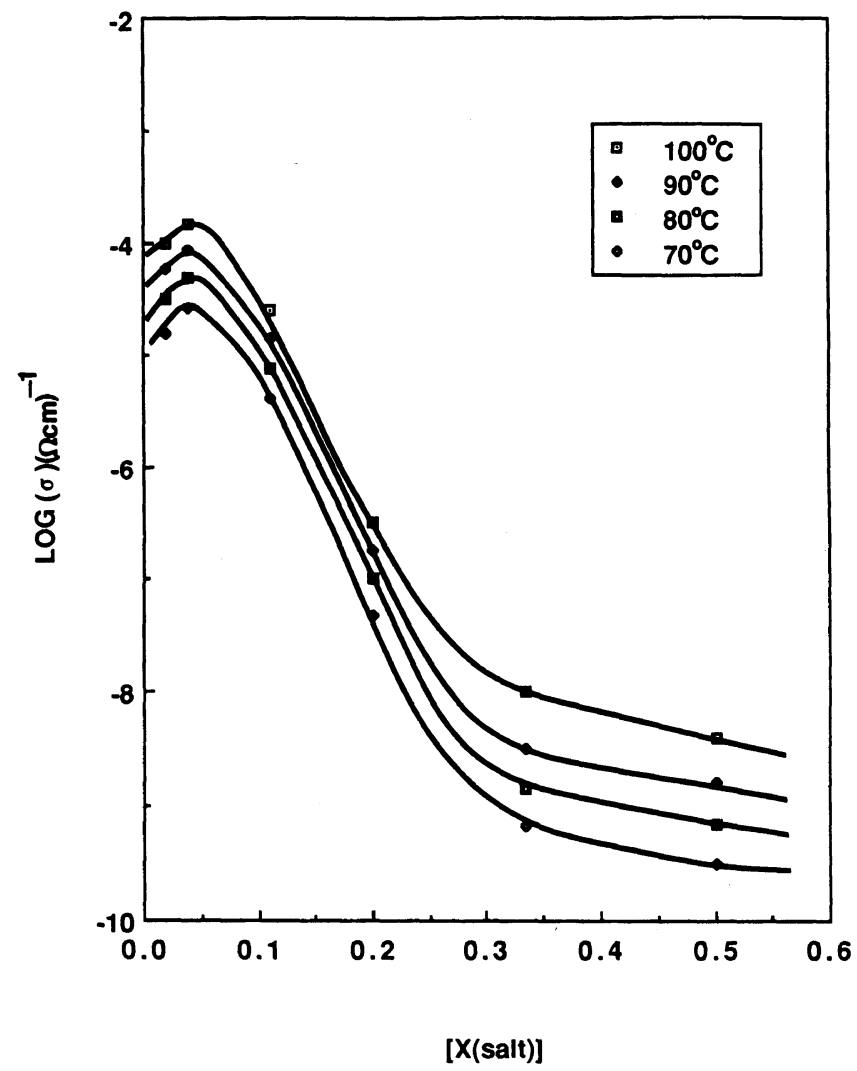

Figure 1. Isotherms of ionic conductivity vs. mole fraction of $\mathrm{LiCF}_{3} \mathrm{SO}_{3}$ in the electrolyte. 


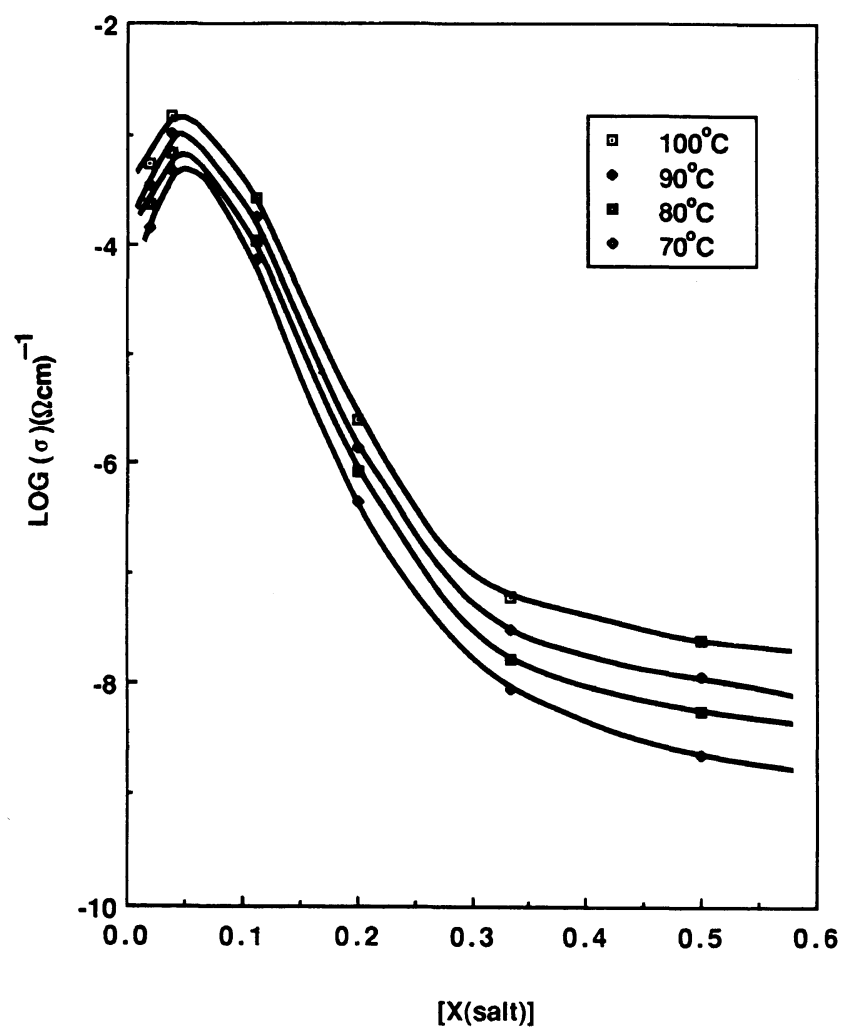

Figure 2. Isotherms of ionic conductivity vs. mole fraction of $\mathrm{LiAsF}_{6}$ in the electrolyte.

To this solution, known weights of PEO were added slowly with constant stirring. In the case of low salt compositions, the solution was homogeneous within a few minutes. However, higher salt concentrations gave lumpy precipitates and these were subsequently stored in sealed bottles for $2-5$ days at $50-100^{\circ} \mathrm{C}$ to homogenize. The final solutions were without precipitates.

Large areas of bubble free films were cast onto Halar sheets in a dry room fume-hood using the doctor blade technique. The films were air-dried in the dry room for several days prior to storing. The films prepared in this way had variable flexibility and opaqueness. The higher salt content films were brittle and opaque as expected. The thickness of the films varied between 10 and $20 \mu \mathrm{m}$. Films of these low thicknesses dried under the above conditions appeared satisfactory with regards to the removal of the solvent. Once dry and solvent free, the electrolyte films were stored in sealed bags for two months to ensure complete crystallization of the complex.

\section{A.c. Conductivity Measurements}

A.c. conductivity measurements were made using the Hewlett Packard 4192 HPLF impedance measurement analyzer in conjunction with a Hewlett Packard 2623A terminal and 7225A plotter. Measurements were made between $5 \mathrm{~Hz}$ and $13 \mathrm{MHz}$ and from room temperature to $110^{\circ} \mathrm{C}$ on cells of the type:

stainless steel | polymer electrolyte $\mid$ stainless steel.

The sample was sandwiched between polished stainless steel electrodes kept under pressure by a spring loaded holder encased in a glass cell design. This was placed in a small tube furnace controlled by a variac. The temperature was monitored (to $\pm 0.2^{\circ} \mathrm{C}$ ) by a 


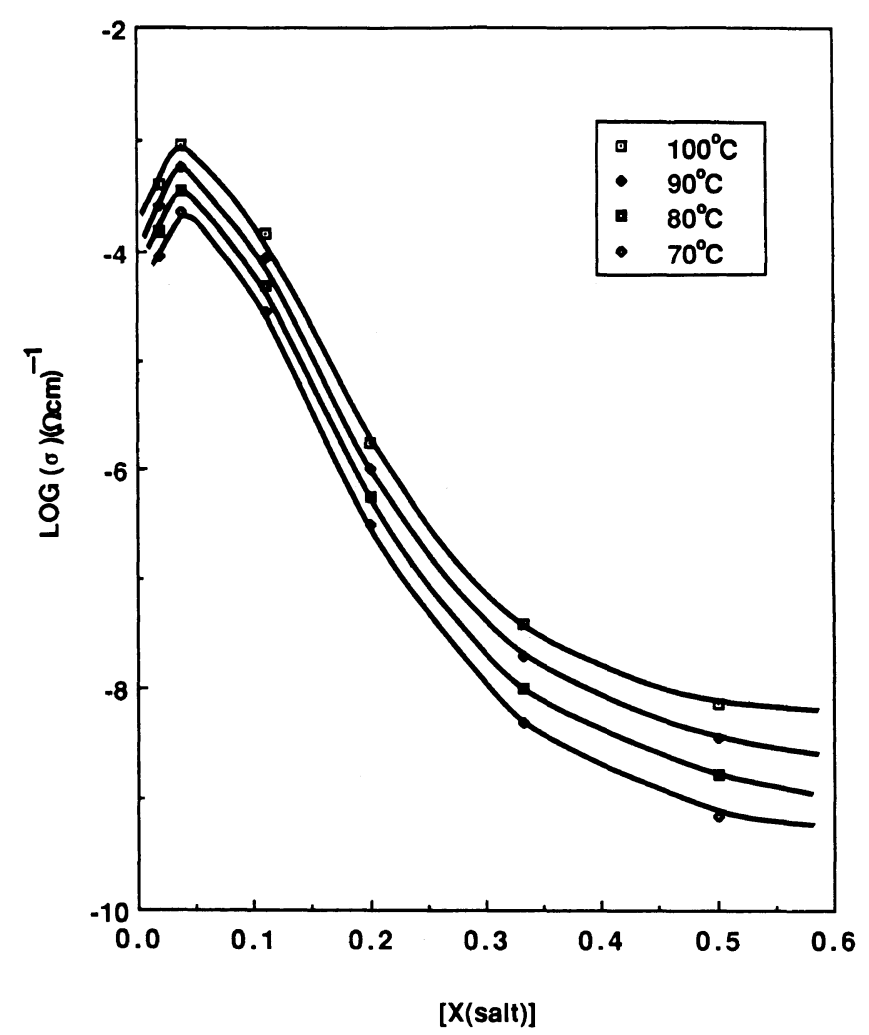

Figure 3. Isotherms of ionic conductivity $v s$. mole fraction of $\mathrm{LiAlCl}_{4}$ in the electrolyte.

chromel-alumel thermocouple placed adjacent to the sample. Measurements were made under vacuum after a sufficient time had been allowed for temperature equilibration. The thickness of the sample exhibited a decrease of about $5 \%$ after the experiment which eventually turned out to be insignificant compared to the overall change.

\section{RESULTS AND DISCUSSION}

Figures $1-5$ show the relationship between the ionic conductivity and composition for PEO-LiX systems at temperatures between $70-100^{\circ} \mathrm{C}$. The results at lower temperatures have been omitted deliberately because the conductivity is extremely low throughout the composition range and therefore unimportant in the discussion. The figures for each system show a conductivity maximum at low salt concentration occurring between $\mathrm{O}: \mathrm{Li}$ ratio of $50: 1$ and $16: 1$. At concentrations greater than $2: 1 \mathrm{O}: \mathrm{Li}$ ratio, there is a levelling off in the conductivity. Between these concentrations (16:1 and $2: 1$ ), the conductivity decreases rapidly with increasing salt concentration. The general shape of the curves is the same for all salt systems studied. This suggests that the mechanism of ionic transport is the same for all systems. It has been suggested ${ }^{24}$ that at temperatures $>60^{\circ} \mathrm{C}$, the $\mathrm{PEO}-\mathrm{LiX}$ systems are two phase (crystalline stoichiometric complex and amorphous phase) with ionic transport occurring in the amorphous phase. Furthermore Arrhenius type behavior is expected rather than a Vogel-Tammen-Fulcher (VTF) on these materials. This is because the molecular movements of the amorphous chains are reduced in highly crystalline polymers such as PEO resulting in a decrease in 


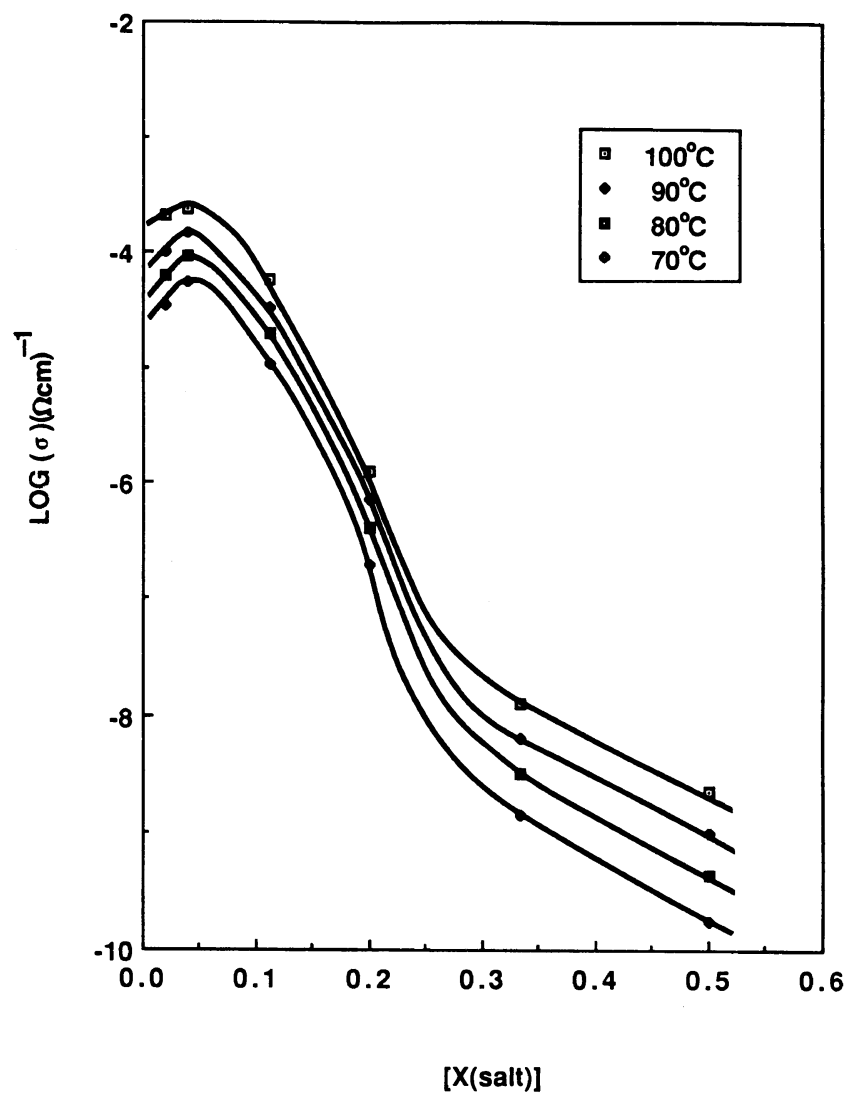

Figure 4. Isotherms of ionic conductivity $v s$. mole fraction of $\mathrm{LiPF}_{6}$ in the electrolyte.

configurational entropy. ${ }^{12}$ X-Ray studies $^{25}$ have shown that the material is highly crystalline, especially at the higher salt concentration. The results ${ }^{25}$ also confirm the absence of free salt in all the films examined except the PEO$\mathrm{LiAlCl}_{4}$ system. Previous studies ${ }^{22}$ on this system also suggested the possibility of $\mathrm{LiAlCl}_{4}$ partially dissociating to $\mathrm{LiCl}$ and $\mathrm{AlCl}_{3}$, although the extent of dissociation was unknown. Sorensen and Jacobsen ${ }^{26}$ proposed a model that characterized the conductivity behavior of the PEO- $\mathrm{LiCF}_{3} \mathrm{SO}_{3}$ system above $70^{\circ} \mathrm{C}$ by the dissolution of the crystalline complex in the amorphous PEO phase. Their result implied a constant mobility of the ion but did not account for the variation in ion mobility with salt composition.

Figure 6 shows the variation in the acti- vation energy versus salt mole fraction. The activation energy of each system was calculated from the Arrhenius expression (1).

$$
\sigma=\sigma_{0} \mathrm{e}^{-\left(E_{\mathrm{a}} / R T\right)}
$$

where $\sigma$ is the ionic conductivity, $R$ is the gas constant, $T$ the absolute temperature and $E_{\text {a }}$ the activation energy.

The results show a minimum in the value of $E_{\text {a }}$ for all the systems studied. This corresponds to a maximum in the conductivity curves (Figures 1-5). At higher salt concentration, the $E_{\mathrm{a}}$ values increase gradually and converge at about $0.9 \mathrm{eV}$. The trend is as follows:

$$
\begin{gathered}
\mathrm{LiBF}_{4}>\mathrm{LiCF}_{3} \mathrm{SO}_{3}>\mathrm{LiPF}_{6}> \\
\mathrm{LiAlCl}_{4}>\mathrm{LiAsF}_{6}
\end{gathered}
$$




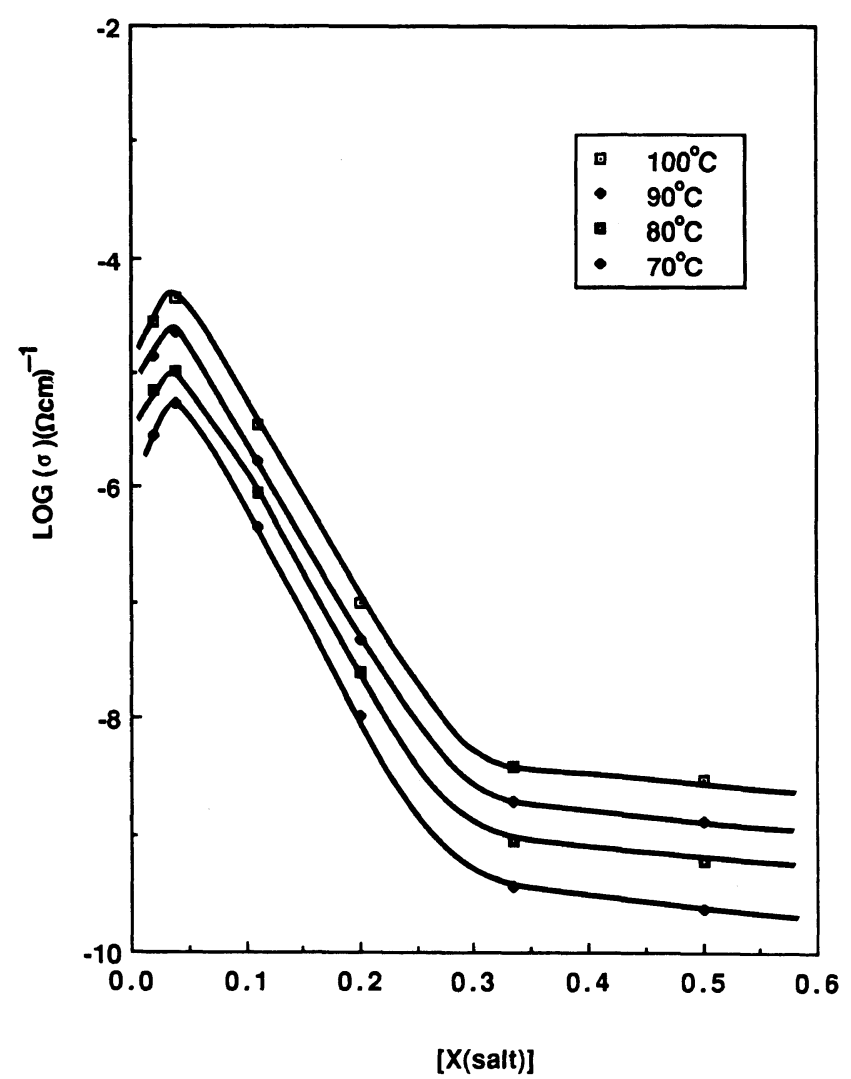

Figure 5. Isotherms of ionic conductivity vs. mole fraction of $\mathrm{LiBF}_{4}$ in the electrolyte.

The general dependence of activation energy on salt composition is in agreement with the work of Sorenson and Jacobsen. ${ }^{26}$ The variation in $E_{\mathrm{a}}$ with different salts suggests that a relationship may exist with the ionic radius. Unfortunately the salts studied have anions that are not spherical. $\mathrm{BF}_{4}{ }^{-27,28}$ and $\mathrm{AlCl}_{4}{ }^{-27,29}$ are regular tetrahedral ions and $\mathrm{AsF}_{6}{ }^{-27,30}$ and $\mathrm{PF}_{6}{ }^{-27,31}$ regular octahedral ions. The structure of the triflate ion $\left(\mathrm{CF}_{3} \mathrm{SO}_{3}{ }^{-}\right)$has recently been studied with complex cations ${ }^{32,33}$ and is neither tetrahedral nor octahedral. The structure consist of a carbon to sulphur single bond flanked by three fluorine and three oxygen ions respectively. Because of the nonspherical nature of the anions, only the maximum possible radius can be considered. The value used for ionic radii are given in Table I.
Table I. Ionic radii

\begin{tabular}{lcc}
\hline Ion & Radius $/ \AA$ & References \\
\hline $\mathrm{Li}^{+}$ & 0.68 & 38 \\
$\mathrm{BF}_{4}{ }^{-}$ & 2.78 & 27,28 \\
$\mathrm{CF}_{3} \mathrm{SO}_{3}^{-}$ & 2.89 & 32,33 \\
$\mathrm{PF}_{6}{ }^{-}$ & 3.08 & 27,31 \\
$\mathrm{AsF}_{6}{ }^{-}$ & 3.2 & 27,30 \\
$\mathrm{AlCl}_{4}$ & 3.93 & 27,29 \\
\hline
\end{tabular}

Figure 7 depicts the variation in the ionic conductivity versus $1 /\left(r_{\mathrm{a}}+r_{\mathrm{c}}\right)$ (for a constant $\mathrm{O}: \mathrm{Li}$ ratio of $50: 1)$ varying with temperature, where $r_{\mathrm{a}}$ and $r_{\mathrm{c}}$ are the anion and cation radius, respectively. Clearly a trend exists between the ionic conductivity and the sum of the ionic radii of the cation and anion. The spread of the points on the curve results from the anions being nonspherical. Despite this, the ionic 


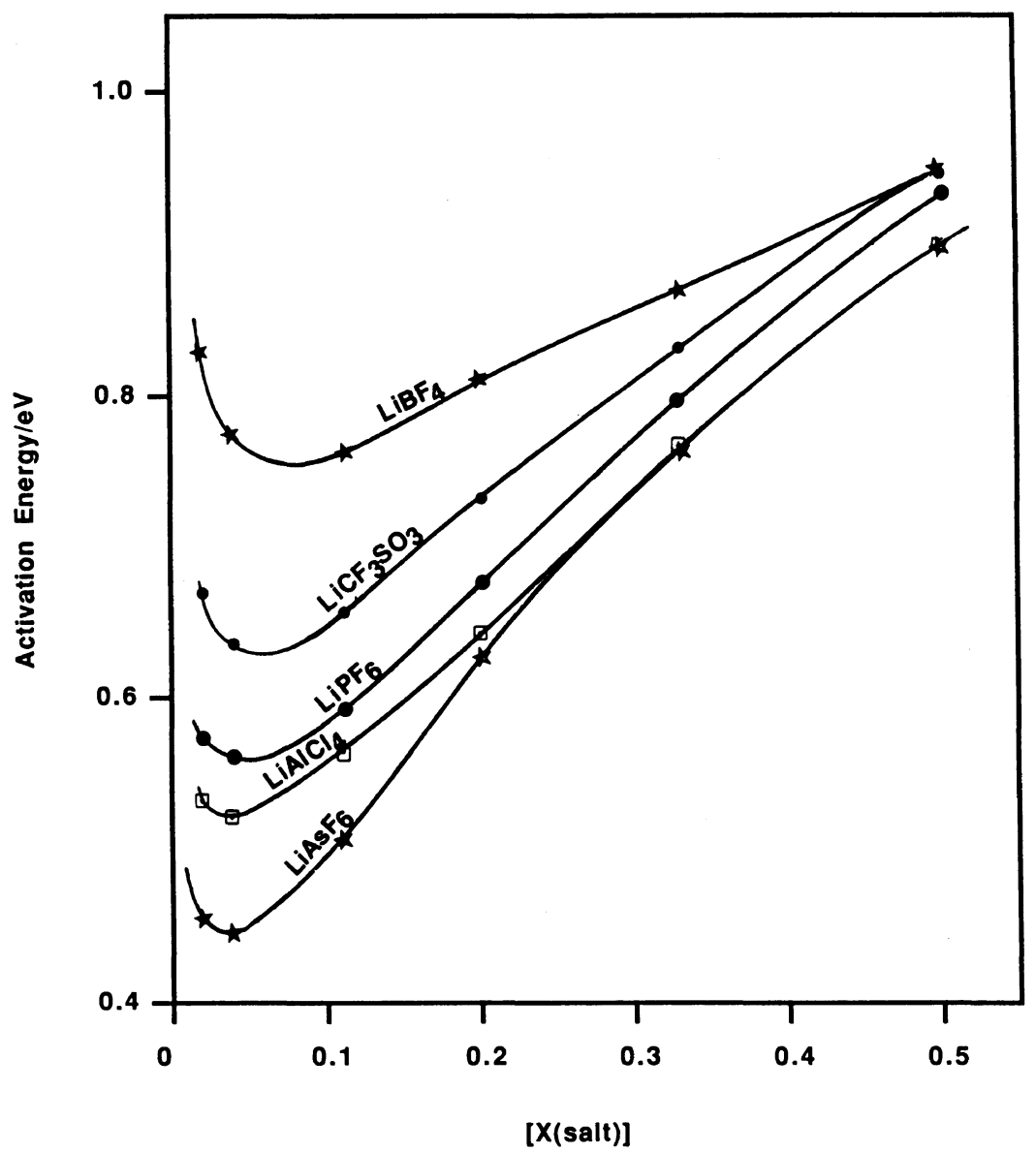

Figure 6. Variations in the activation energy $v s$. salt mole fractions.

conductivity increases as the ionic radii of the cation and anion increase up to about $4 \AA$. At this point a maximum is found and further increase in the ionic radii results in a decrease in the conductivity. The figure shows that this trend is maintained at lower temperatures but the overall conductivity is lower.

Figure 8 shows the variation in the ionic conductivity versus $1 /\left(r_{\mathrm{a}}+r_{\mathrm{c}}\right)$ for different $\mathrm{O}: \mathrm{Li}$ ratios but at a constant temperature of $100^{\circ} \mathrm{C}$. The trend is again similar but in this case the overall conductivity decreases with increasing salt concentration above an $\mathrm{O}: \mathrm{Li}$ ratio of $25: 1$.

The above result demonstrates that anions do play a considerable part in influencing the ionic conductivity of the polymer electrolyte. As noted previously, ${ }^{10}$ ionic conduction in polymeric materials results from carrier ion hopping from site to site. The most stable hopping sites considered by these authors are the anions. In the case of an ion-pair formation, the energy required to separate these ions is given by

$$
\Delta E=\frac{e^{2}}{4 \pi \varepsilon_{0} \varepsilon} \cdot \frac{1}{\left(r_{\mathrm{a}}+r_{\mathrm{c}}\right)}
$$

where $\varepsilon$ is the dielectric constant in vacuum and $\varepsilon_{0}$ the diclectric constant of the medium.

Hence as the ionic size of the salt increases, the energy required for ion separation decreases. This is reflected in the increase in the 


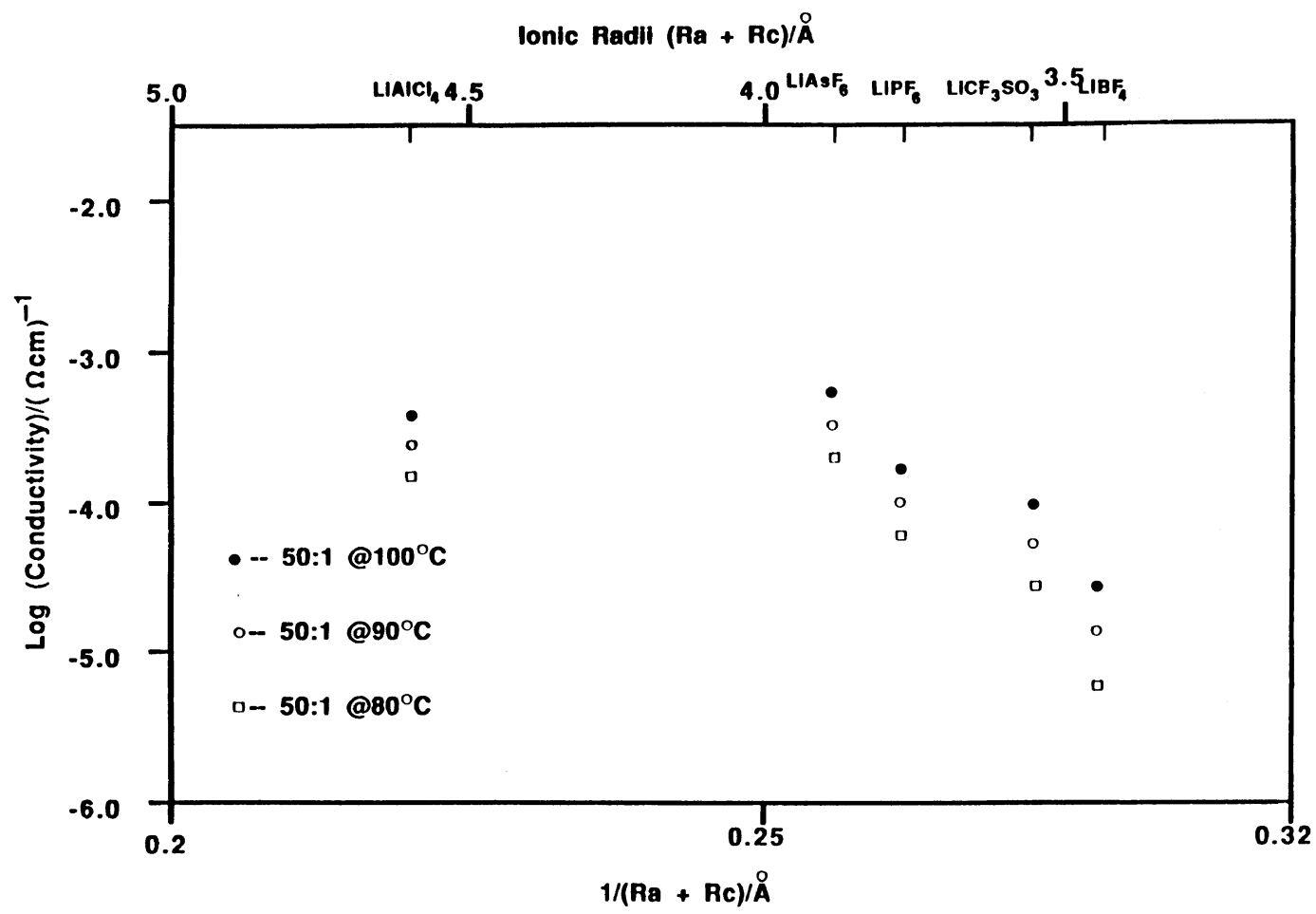

Figure 7. Variation in the ionic conductivity $v$ s. ionic radii of cation and anion for a fixed $\mathrm{O}:$ Li ratio varying with temperature.

ionic conductivity of the electrolyte. However, when the variation of the ionic conductivity versus the ionic radii are presented in the form of Figures 7 and 8 , it is clear that simple models alone cannot explain the ionic dependence over a large span of the radii. The fact that the conductivity decreases with increasing salt concentration (Figures 1-5) demonstrates that cation-anion interactions do play a major role. It is evident that the PEO molecules must adopt a type of configuration in which the oxygen lone pairs are oriented in such a way as to result in the lowest free energy. This would occur if the lone pair orbitals were pointing as much away from one another. Under these conditions the cation to lone pair linkages take place with four different strands or helices, e.g., for a 4:1 stoichiometry. Other configurations are possible such as two or more linkages from the same helix. However, con- siderable strain is then put on the molecule. The bonding between the lone pair on the oxygen from PEO and $\mathrm{Li}^{+}$are considered to be coordinate covalent. The solution behavior of PEO and lithium salts can be closely compared to the solution behavior of lithium salts dissolved in water. The PEO in this respect behaves in a similar way to water molecules in that four linkage are made between the lithium ion and the oxygen lone pair from each PEO unit. But whereas the water molecules are arranged in a tetrahedral manner, the helical nature of the PEO fibers prevents this conformation. It has been suggested ${ }^{34}$ that the PEO molecules are labile and the bonding between the oxygen lone pairs and lithium ion are also labile. This implies that the anions are either partially bonded to the lithium ion or "floating" in the polymer matrix surrounded by weakly bonded PEO molecules. This is be- 


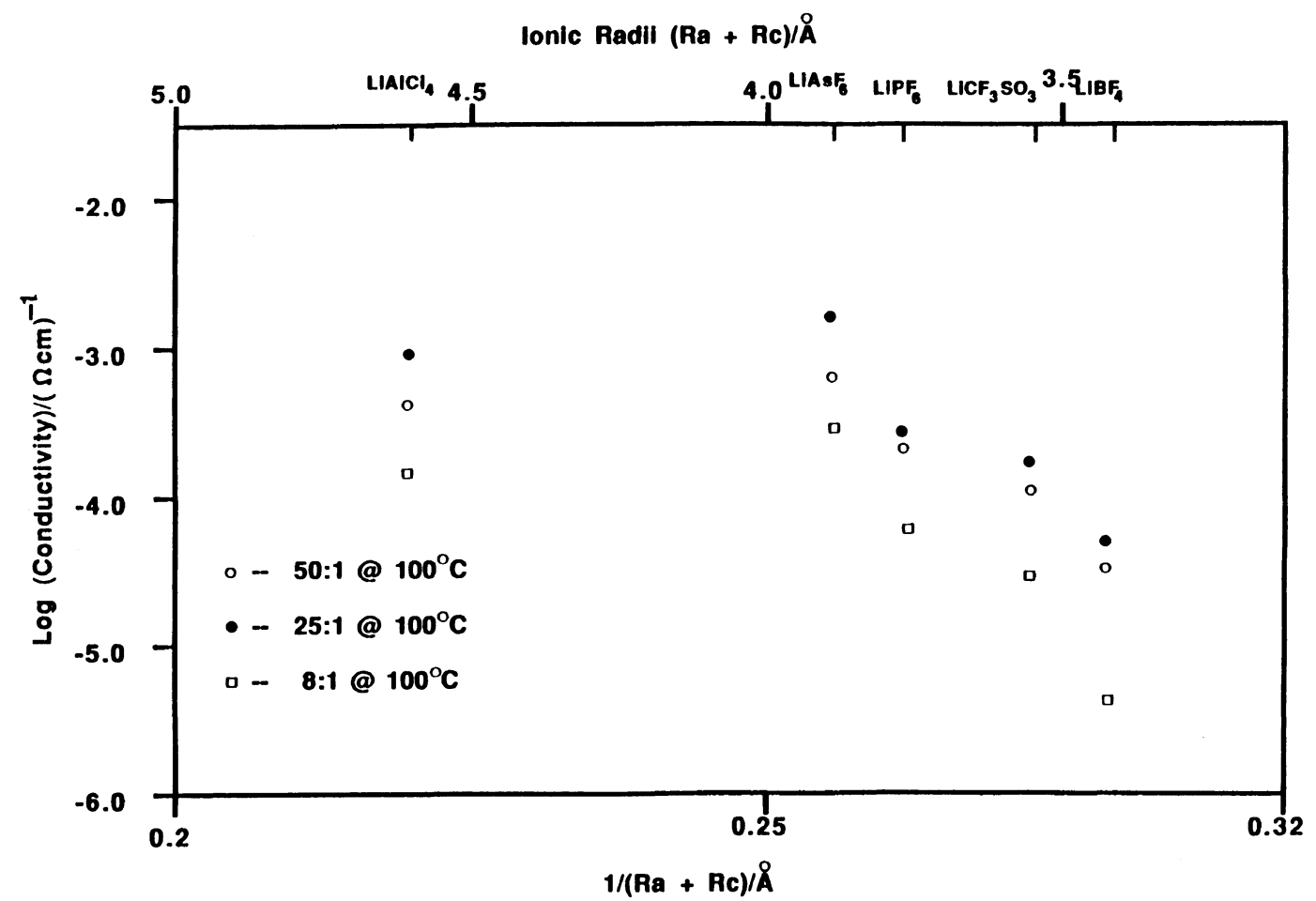

Figure 8. Variation in the ionic conductivity $v s$. ionic radii of cation and anion at $100^{\circ} \mathrm{C}$ for different $\mathrm{O}: \mathrm{Li}$ ratios.

cause the shape of the anion are not spherical, unlike the cation, and hence any strong bonding by the PEO helices would result in serious compressional strain on the PEO strands from coulombic repulsion from the oxygen lone pair of electrons.

Furthermore, whether or not ion-pairing readily occurs depends on the free-energy changes and this is concentration dependent. The free energy change for the reaction

$$
\mathrm{Li}^{+}+\mathrm{X}^{-}--\rightarrow \mathrm{LiX} \text { (ion pair) }
$$

is given by

$$
\Delta G_{(\text {Reaction })}^{0}=\Delta G_{\mathrm{f}(\text { Product })}^{0}-\Delta G_{\mathrm{f}(\text { Reactant })}^{0}
$$

where $\Delta G_{\mathrm{f}(\text { Product })}^{0}$ and $\Delta G_{\mathrm{f}(\text { Reactant) }}^{0}$ represent the total free energies of formation of the product and reactants, respectively.

If the reaction 3 is favored to the left, then $\Delta G$ is positive, and hence, the lithium ions attach themselves to the PEO network.
However, at some point in salt concentration, equilibrium is reached and ion-pair formation is the favorable reaction. In aqueous media this would occur with a levelling off in the conductivity as the salt saturation limit is reached. This is a direct result of the high dielectric constant of water in which ion pairing is least favored.

In the PEO system, the dielectric constant is $\operatorname{low}^{35}(\varepsilon=5)$, and at some point the ionic conductivity decreases with increasing salt concentration (Figures $1-5$ ). It is suggested that this results from ion-pair formation between the cation and anion. The interaction between PEO and the lithium ion is reduced and the mobility of $\mathrm{Li}$ ion hopping from oxygen lone pair to lone pair becomes seriously impaired. Consequently the activation energy increases. This is analogous to the behavior of lithium salts in low dielectric constant solvents. ${ }^{36,37}$ The fact that the conductivity decreases be- 
yond a particular ionic radius suggests that steric hindrances by the anions take place and obstruct the movement of lithium ions. The simple model proposed above seems to be in accord with experimental observations.

\section{CONCLUSION}

The ionic conductivity behavior of PEO complexed with lithium salts was investigated over a wide composition range. The result showed that anions strongly influence the conductivity of the polymer electrolyte. A simple model was proposed whereby the conductivity decrease at higher salt concentration was explained as due to ion-pair formation.

Acknowledgement. The authors are grateful to Professors W. Reynolds and D. Britton (Dept. of Chemistry) for many helpful discussions. This work was supported in part by the Office of Naval Research.

\section{REFERENCES}

1. B. E. Fenton, J. M. Parker, and P. V. Wright, Polymer, 14, 589 (1973).

2. M. B. Armand, J. M. Chabogno, and M. J. Duclot, "Fast Ion Transport in Solids," P. Vashista, J. N. Mundy, and G. K. Shenoy, Ed., North-Holland, Amsterdam, 1979, p 131.

3. M. Armand, J. M. Chabogno, M. Duclot, 2nd Int. Meet. on Solid Electrolytes, Ext. Abs., St. Andrews, Scotland (Sept. 20-22, 1978).

4. D. F. Shriver, B. L. Papke, M. A. Ratner, R. Dupon, T. Wong, and M. Brodwin, Solid State Ionics, 5, 83 (1981).

5. A. Killis, J. F. LeNest, and H. Cheradame, Makromol. Chem., Rapid Commun., 1, 595 (1980).

6. A. Killis, J. F. LeNest, A. Gandini, and $H$. Cheradame, J. Polym. Sci., Polym. Phys., Ed., 19, 1073 (1981).

7. J. E. Weston and B. C. H. Steele, Solid State Ionics, 7, 81 (1982).

8. D. F. Shriver, R. Dupon, and M. Ratner, Electrochem. Soc., Ext. Abst. 83.1 \#490, San Francisco, 1983.

9. M. Watanabe, K. Sanui, N. Ogata, F. Inque, T. Kobayashi, and Z. Ohtaki, Polym. J., 16, 711 (1984).

10. M. Watanabe, K. Nagaoka, M. Kanba, and I. Shinohara, Polym. J., 14, 877 (1982).

11. M. Watanabe, J. Ikeda, and I. Shinohara, Polym. J., 15, 65 (1983).
12. B. L. Papke, M. A. Ratner, and D. F. Shriver, J. Electrochem. Soc., 129, 1694 (1982).

13. C. Berthier, W. Gorecki, M. Minier, M. B. Armand, J. M. Chabagna, and P. Rigand, Solid State Ionics, 11, 91 (1983).

14. P. M. Blonsky, D. F. Shriver, P. Austin, and H. R. Allcock, Solid State Ionics, 18/19, 258 (1986).

15. P. Ferloni, G. Chiodelli, A. Magistris, and M. Sanesi, Solid State Ionics, 18/19, 265 (1986).

16. D. Teeters and R. Frech, Solid State Ionics, 18/19, 271 (1986).

17. F. M. Gray, J. R. MacCallum, and C. A. Vincent, Solid State Ionics, 18/19, 282 (1986).

18. L. L. Yang, R. Hug, G. C. Farrington, and G. Chiodelli, Solid State Ionics, 18/19, 291 (1986).

19. C. K. Chiang, G. T. Davis, C. A. Harding, and T. Takahashi, Solid State Ionics, 18/19, 300 (1986).

20. M. Watanabe, S. Nagano, K. Sanui, and N. Ogata, Solid State Ionics, 18/19, 338 (1986).

21. T. Hibma, Solid State Ionics, 9/10, 1101 (1983).

22. M. Z. A. Munshi and B. B. Owens, Appl. Phys. Commun., 6(4), 279 (1986-87).

23. B. K. Sen and S. Sen, The 6th Ris $\phi$ International Symposium on Material Science, Sept. 9-13, Denmark, 1985.

24. W. Gorecki, PhD Thesis, Grenoble University, France, 1984

25. M. Z. A. Munshi and B. B. Owens, to be published.

26. P. R. Sorensen and T. Jacobsen, Polym. Bull., 9, 47 (1983).

27. Tables of Interatomic Distances and Configuration in Molecules and Ions, No. 11, The Chem. Soc., London, 1958.

28. A. Bellanca and F. Sgarlata, Rend. Soc. Mineralog. Ital., 7, 42 (1951).

29. N. C. Baenziger, Acta Crystallogr., 4, 216 (1951).

30. R. B. Roof, Acta Crystallogr., 8, 739 (1955).

31. H. Bode and G. Teufer, Acta Crystallogr., 8, 661 (1955).

32. B. Krebs, G. Henkel, S. Pohl, and H. W. Roesky, Chem. Ber., 113, 226 (1980).

33. V. B. Ganswein and G. Brauer, Z. Anorg. Allg. Chem., 415, 125 (1975).

34. W. Reynolds, Univ. of Minnesota, U.S.A., private communication.

35. N. G. McCrum, B. E. Read, and G. Williams, "Inelastic and Dielectric Effects in Polymeric Solids," John Wiley and Sons, New York, N. Y., 1967.

36. G. E. Blomgren, "Lithium Batteries," J. P. Gabano, Ed., Academic Press, New'York, N. Y., 1983, p 38.

37. G. E. Blomgren, "Power Sources for Biomedical Implantable Applications and Ambient Temperature Lithium Batteries,' Proc. Vol. 80-4, the Electrochem. Soc., Princeton, N. J., 1900, p 368.

38. Handbook of Chemistry/Physics, 68th ed, R. C. Weast, Ed., CRC Press, 1987-1988, p F-159. 